\title{
Implementation of medication management services at the primary healthcare level - a pilot study
}

\author{
ANDREA BRAJKOVIĆ ${ }^{1}$ \\ IVA MUCALO ${ }^{1, *}$ \\ TONI VIDOVIĆ ${ }^{2}$ \\ MARIANA MARTINS GONZAGA \\ DO NASCIMENTO 3 \\ ANTONIJA BALENOVIĆ ${ }^{4}$ \\ INO PROTRKA ${ }^{4}$ \\ DJENANE RAMALHO DE OLIVEIRA ${ }^{3}$ \\ ${ }^{1}$ University of Zagreb Faculty of Pharmacy \\ and Biochemistry, Zagreb, Croatia \\ ${ }^{2}$ Zagreb City Pharmacy, Zagreb, Croatia \\ ${ }^{3}$ Centre for Pharmaceutical Care Studies \\ (Centro de Estudos Atencao Farmaceutica) \\ Federal University of Minas Gerais \\ Belo Horizonte, MG, Brazil \\ ${ }^{4}$ Health Centre Zagreb - Centre, Zagreb \\ Croatia
}

Accepted July 23, 2019

Published online September 6, 2019

\begin{abstract}
This study employed a mixed-method approach to enable the implementation of comprehensive medication management (CMM) services in Croatia's primary care setting. Drug therapy problems (DTPs) and factors associated with their occurrence were determined in patients with chronic diseases from January 2018 to April 2019. The pre-implementation stage established the foundations for the early implementation stage, in which the practice was set up, the patients' recruitment initiated and various challenges identified. During the study period, 86 patients were recruited for CMM provision. Overall, 2.8 DTPs $( \pm 1.6)$ per patient were identified and the majority $(96.2 \%)$ presented with at least one DTP. Multiple regression analysis showed that type 2 diabetic patients $(p=0.025)$ and patients using five or more medications $(p=0.011)$ should be prioritized to receive CMM services as potentially they have a higher number of DTPs, and could, therefore, obtain a greater benefit from the service.
\end{abstract}

Keywords: comprehensive medication management services, drug therapy problems, risk factors, pharmaceutical care, primary care, implementation stage

Pharmaceuticals are the most common medical intervention and their ability to control disease and impact overall cost, morbidity, and productivity, when appropriately used, is enormous $(1,2)$. According to the latest OECD publication "Health at a Glance: Europe 2018", pharmaceuticals expenditure, including prescription and over-the-counter medications, presented the third largest item of health care spending in the European Union (EU) (3). Croatia is among the EU Member States with the highest expenditure on medical goods, mainly pharmaceuticals, amounting to $28.5 \%$, compared to an EU average of $18.5 \%$ (3). Moreover, mortality rates from cardiovascular diseases are almost double the EU average and mortality rates from lung, breast and colorectal cancer are among the highest in the EU, pointing to shortcomings in health care delivery and public health interventions in Croatia (3).

\footnotetext{
*Correspondence; e-mail: imucalo@pharma.hr
} 
In addition, a continuous increase in the prevalence of chronic medical conditions is expected alongside the accompanying polypharmacy (4). This scenario renders chronic patients at an increased risk of experiencing drug therapy problems (DTPs), hence adding substantial costs to the health care system and exceeding the amount spent on the medications themselves (5-7).

New approaches are needed at an individual and population level to provide safe and effective pharmacotherapy to patients in an ever more complex environment (8). Thus, to ensure patients' optimal medication use and improve their clinical outcomes, comprehensive and systematic management of medications is deemed crucial. Comprehensive Medication Management (CMM) services (9), officially recognized by the Federal Government of the USA in 2003 (MMA 2003) (10), address this problem. The provision of CMM involves a logical and patient-centered approach to medication optimization that ensures every medication used by a patient is appropriate, effective, safe and convenient to be taken. Almost 30 years have passed since Hepler and Strand had defined pharmaceutical care as a practice in which a pharmacist-practitioner takes the responsibility for a patient's drug-related needs by identifying, resolving and preventing DTPs (9). Collaborative practice between pharmacists and general practitioners (GPs), together with patients' active participation in the definition of treatment regimens, plays an important role in the effectiveness of CMM services (9). Apart from the USA, several countries (e.g. Great Britain, Australia, Canada and Brazil) have managed to integrate CMM services into their existing health care system at the primary care level (11-16).

In January 2018, CMM services were introduced as a pilot project in the largest county health centre in Croatia - Health Centre Zagreb - Centre, thus becoming the first and, at the moment, the only health centre in Croatia and South-Eastern Europe providing CMM by using the patient care process proposed by Cipolle et al. (9). However, until now little descriptive and in-depth comparative qualitative work has been published to broaden the understanding regarding the process of implementation of CMM services. Therefore, the primary aim of this study is to describe the newly implemented practice management system of CMM services at the county health centre in Croatia. In addition, various studies have demonstrated its effectiveness on clinical (14, 15, 17-24), economic (17, 22, 23, 25) and humanistic outcomes $(26,27)$. Other studies determined some factors associated with the occurrence of DTPs, such as polypharmacy, multimorbidity and age, yet employed methodology or clinical settings dissimilar to the present study (28-31). However, to the best of authors' knowledge, until now, no study determined the associated factors of patients with chronic diseases at the primary care level as they receive CMM services that follow the theoretical framework proposed by Cipolle et al. (9). Therefore, the secondary aim of the present study was to describe the DTPs and to determine the factors associated with their occurrence among general ambulatory patients receiving CMM services at the primary care level.

\section{EXPERIMENTAL}

\section{Study design}

In this paper, a mixed-method methodology, involving the use of a combination of qualitative and quantitative approaches to data gathering, was employed. The first part was a qualitative study that used an action research methodology with the aim of implementing CMM services, a new patient care service in the Croatian primary health-care 
system, and describing the implementation processes involved. Action research followed the procedures proposed by Kurt Lewin (32), its founder, who assumed that human systems can only be understood and changed if their members take part in this process. Considering the complexity involved in implementing a new health service in the Croatian health system, such as CMM services, this approach was suitable for the herein present study. Within the active research strategy, the first two authors were active in implementing and providing the service, that is, being practitioners, while at the same time they were gathering and analysing data, or acting as researchers.

The implementation stages utilized previously published research as a roadmap $(33,34)$, which was adapted to the Croatian reality as needed. Additionally, the previously proposed implementation system assisted the piloting of the initial implementation of CMM services through two stages: pre-implementation and early implementation (34). The pre-implementation stage encompassed the following components: ensuring a usable innovation (use of a common language for the CMM philosophy of practice and patient care process), building an implementation team, developing practitioners' readiness to provide the service, identifying and ensuring essential practice management support (infrastructure necessary to ensure the capacity to implement CMM), assessing fidelity of the service and establishing a practice-policy loop.

The second part, the quantitative approach, was a prospective, observational study on CMM services provided to ambulatory patients that was conducted from January 2018 to April 2019 at the primary care clinic, Health Centre Zagreb - Centre (HCZC), with an aim of describing DTPs and determining the factors associated with their occurrence. These results are a part of a larger study designed as an open controlled pre- and post-intervention study with a 1-year patient follow-up. Thus, this paper presents a secondary subset analysis of trial data evaluating the impact generated by a CMM service in patients with chronic health conditions as a primary outcome measure (unpublished to date).

\section{Setting}

The CMM services outlined in the present study are piloted in an independent counseling unit, Pharmacotherapy counselling service, located in the county health centre, HCZC. This is a primary health care institution and the largest health centre in the Republic of Croatia with 101 active GPs teams. The HCZC's CMM service, developed in partnership with the University of Zagreb Faculty of Pharmacy and Biochemistry (UoZ) as a part of the joint research project, was established in January 2018 to help patients manage their chronic health conditions and optimize the therapeutic value of medicines. Until now, this is the only health centre in the country providing CMM services at the primary care level in Croatia. Two pharmacists from the UoZ Faculty of Pharmacy and Biochemistry facilitated the implementation of the CMM services in the health centre by using the same standardized patient care process (18). CMM services were provided to patients with chronic conditions taking multiple medications, but who were not meeting their therapy goals. Based on the pre-defined inclusion criteria, GPs identified patients and referred them to the pharmacist. The inclusion criteria were the following: a) patients who have not reached or are not maintaining the intended therapy goal, b) patients experiencing adverse effects from their medications, c) patients having difficulty understanding and following their medication regimen, d) patients in need of preventive therapy, and e) patients frequently readmitted to hospital. The initial assessment lasted 60-90 minutes and the follow- 
up evaluations 30-60 minutes. Alternatively, patients were followed-up by telephone. The infrastructure needed for the provision of the service, including the space facilitating the delivery of quality service, access to patients, access to the patients' health care providers and administrative support, was ensured by the HCZC. Furthermore, newly implemented electronic consultation system (Health.net PRO) (35) at the HCZC enabled GPs to consult with both, hospital medical specialists and practising pharmacists providing CMM services, thus creating a unique platform for patient referral and care plan sharing. Aside from GPs and pharmacists, no other health care professionals were present within this setting.

\section{Data collection}

Qualitative data. - Data were collected through semi-structured interviews, group meetings (focus-groups), participant observation, and field journals with descriptions and reflections on the process of implementing and delivering comprehensive medication management services. Semi-structured interviews and group meetings were conducted with GPs and other stakeholders (health policy experts and health-system experts) for sixteen months, and a total of twenty GPs and three members of the management board of the health centre participated in this study.

Both unstructured interviews and group meetings served to introduce the service to GPs, but also to study their views on today's status of the health care system in general, their perspectives on medicine use and rational medication use, and the need for introducing medication management services in the ambulatory clinic. The group meetings allowed discussions regarding the benefits and outcomes of integrating medication management services with other existent services, the types of patients that could benefit most from the service, the value of the service, and their expectations related to the new service. Moreover, practicalities like the structure of a patient's personal medication plan and communication channels between pharmacists and GPs were examined. Since the beginning of the project, twenty-five meetings with the Head of the family medicine specialists took place to share ideas and updates on the progress of the project, and to create new solutions for the advancement of the service.

To encourage and sustain the reflectivity of the team, discussions between the two practitioners-researchers were being held on a weekly basis, and with their trainer, a highly experienced researcher, on a monthly basis. Moreover, participant observation involving journaling and reflection by the practitioners/researchers occurred during the entire implementation period to reach an in-depth understanding of experiences, feelings and actions practitioners lived through during this time. Pharmacists' experiences with the patient-caring process, descriptions of the events that depicted the project's process, ideas for project development and the vision for the CMM services in the future including the remuneration options, were being kept.

As abovementioned, in order to minimise research bias and enhance the validity of the results, triangulation of different methods of data collection and researcher reflexivity was employed. As previously emphasized, once a proposition has been confirmed by more than one independent measurement process, the level of uncertainty surrounding it is reduced (36).

Quantitative data. - Data was collected from CMM interventions with patients which ran from January 2018 to April 2019. Patients were eligible for the participation if they were aged 18 years or more with at least one regular prescription medication and were admitted fol- 
lowing referral by their general practitioner or self-referral. Data were retrieved by a careful review of paper and electronic medical records, and through the interview with the patient, or a patient's family member or a caregiver, if needed. Subsequently, the data were entered into the CMM documentation system that stored all the patients' records. The extracted data contained the following fields: patients' demographics, current and previous medical conditions, number of medications taken, history of drug allergy and adverse drug reactions, number of CMM consultations, types of drug therapy problems identified and addressed, types of interventions implemented to resolve drug therapy problems and change in patients' clinical status. Prescription medications for chronic conditions and all active over-the-counter (OTC) medications, as well as herbal remedies, supplements and medications used for a limited period of time were included in the analysis. The principal diagnosis and comorbidities were coded according to the International Classification of Diseases (ICD-10 Version: 2016) and Anatomical Therapeutic Chemical (ATC) Classification codes were used to analyse the drug therapy. Patients using methadone and other patients with addiction problems, mental and behavioural disorders due to psychoactive substance use and patients with cognitive impairment were not deemed eligible and were thus excluded from the study. The study protocol was approved by the Health Centre's Ethics Committee and the Ethics Committee of the University of Zagreb Faculty of Pharmacy and Biochemistry. This study followed guidelines of the Declaration of Helsinki and Tokyo.

\section{The patient care process}

The patient care service employed in this study, namely CMM service, followed the philosophy and the standardized patient care process proposed by Cipolle et al. (9). Each $\mathrm{CMM}$ encounter was based on the rational decision-making process referred to as the Pharmacotherapy Workup (9). This process represents cognitive work taking place in the

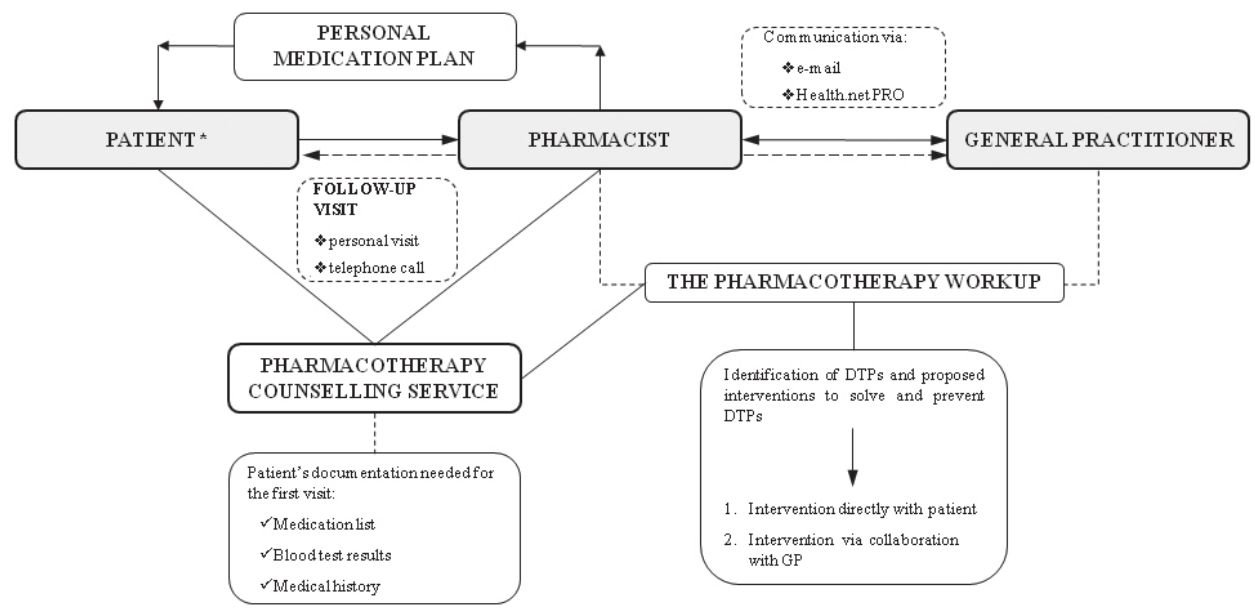

\footnotetext{
* Type of patient's referral to Pharmacotherapy counselling service: GP referral; Self-referral; Other (family/friend recommendation, specialist referral).
}

Fig. 1. Workflow diagram of CMM services. 
mind of the practitioner and is used to identify, resolve, and prevent DTPs, establish therapy goals, select interventions and evaluate actual outcomes. Identifying a DTP required the practitioner to establish an association between the patient's medical condition and the patient's pharmacotherapy with the purpose of determining whether the patient's drug-related needs were being met. Patients' DTPs identified and addressed by CMM pharmacists were categorized into seven groups (Appendix A) and always assessed in the same systematic order; first, the appropriateness of the drug therapy, followed by the effectiveness of drug regimen, safety and at the last place, adherence. Moreover, this standardized process is implemented in a patient-centred manner, which takes the patient's unique circumstances, needs and expectations into consideration. The workflow of the patient care process specific for Croatian primary care level is shown in Fig. 1.

\section{Study variables and data analysis}

The independent variables included demographic characteristics of a patient (age, sex and employment status), anthropometric and clinical (number of diseases, number of drugs used, diagnosis of cardiovascular disease, hypertension, dyslipidaemia or diabetes, hospitalization and emergency department visit recorded in the previous year) and smoking status. The sum of the DTPs detected during the first and second consultation was dichotomized (0-2 DTP; $\geq 3$ DTP) and defined as the dependent variable. Quantitative variables were described according to their mean, standard deviation, median and interquartile range, while categorical variables were shown as frequency and percentage.

Pearson's Chi-squared test or Fisher's exact test were used to assess univariate analyses between the independent variables and the DTP presence. Independent variables with $p<0.15$ in the univariate analyses were included in a multivariable logistic regression model to identify factors associated with the dependent variable. Taking into consideration that the univariate analysis represents the initial step to the associated factors analysis, the higher $p<$ value $(p<0.15)$ was selected to ensure that no important variable was left outside the final and multivariate analysis. To evaluate the goodness of fit of the model, the Hosmer-Lemeshow test was used and a likelihood ratio test was used to compare the models. A $p<0.05$ was considered statistically significant in all analyses. All of the data were analysed with the IBM SPSS software, version 22.0 (SPSS Inc, Chicago, SAD).

\section{RESULTS AND DISCUSSION}

\section{Qualitative results}

Piloting the implementation of the CMM services in the county health centre. - The following description depicts observations, understandings and experiences of implementing CMM services at the primary care clinic, HCZC in Zagreb, Croatia for the first time.

Pre-implementation (preparation). - Three years prior to the commencement of the pilot project, an implementation team of five members was established, each member with a unique role and set of skills in the areas of pharmacy practice, clinical pharmacy, quality improvement, primary care, health systems in transition and health care reforms. The team assembled periodically to discuss and set the grounds for the implementation of the 
new service. Firstly, the suitability of various primary care practice sites was explored to determine whether the structural (private consultation room, documentation system, access to evidence-based information) and system-level support systems (support of clinic leadership and primary care physicians) were in place to facilitate the successful implementation of the CMM services. To ascertain that, a series of interviews with health centres managers and GPs across multiple study sites were conducted over a period of one year, until an agreement with an interested health centre was reached and the availability of the practice management infrastructure was assured.

Furthermore, the identification of an 'in-house' key person interested in initiating this innovation, in this case, the Head of family medicine specialists, was of paramount importance, as he facilitated the introduction of the new service into the health centre. Utilizing the vast scientific literature already published in different countries about the impact of CMM services $(18,19,21,24)$, the perceived need and the benefits of this innovation were communicated with the Director of Health Care Centre and the Head of the family medicine specialists over four group meetings during a two-month period. Openness and eagerness of the management board to allow the piloting of the new service was seen as the rate-increasing step for the outset of the project.

Although this study describes a pilot project, and not a full-service implementation (remuneration was not ensured for practicing pharmacists), fidelity measures were undertaken through a series of steps. Bearing in mind the importance of ensuring a usable innovation, it was made sure that both pharmacists providing the service spoke a common language and delivered the same standards of care, which was achieved through a shared commitment to the philosophy of practice that underlies the CMM patient care process (9).

Furthermore, to ensure both pharmacists at the primary care clinic were prepared to engage in the implementation of the service, several learning strategies were employed. During a three-month doctoral internship at the Centre for Pharmaceutical Care Studies, Federal University of Minas Gerais in Belo Horizonte, Brazil, the philosophy of pharmaceutical care practice and the core elements of CMM services were mastered by the younger researcher (PhD student). Learning resources, such as documents overviewing CMM patient care process and the philosophy of practice (37), on-line training, coaching calls and access to real-life practice to provide a forum for sharing lessons learned, were utilised to equip both pharmacists with the skills and knowledge necessary to successfully commence with the implementation process. Additionally, a relationship with a highly experienced researcher, practitioner and trainer was established and maintained throughout the project. The trainer's continuous assistance and coaching provided through regular telephone meetings was invaluable for the piloting process. Besides the required transformation in pharmacists' attitudes and behaviours, CMM services are a multi-layered service requiring a profound knowledge-base in pharmacotherapy. Hence, a connection was established with several medical specialists who provided external support by covering multiple content areas (e.g. endocrinology $(N=2)$, cardiology $(N=1)$, pulmonology $(N=1)$, ophthalmology $(N$ $=1)$ and nephrology $(N=1))$. Finally, to keep pace with the ever-evolving field of pharmacotherapy, evidence-based literature (38-40) and clinical decision support systems (41) were consulted. Additionally, lecture-based courses covering various pharmacotherapy topics were continuously attended.

Subsequently, establishing and standardizing workflow and a management system unique to this specific health centre was a challenging assignment for the team members. 
Three group meetings and two working sessions were carried out for both implementation team members and external consultants recruited to provide support. This work resulted in the development of the document describing the work process flow, namely GP-pharmacist-patient communication, the process of referring patients to a pharmacist, various channels of GP-pharmacist communication, the layout of patients' output documents and other aspects of the practice management system. Components of the practice management system adapted to Croatian primary health care setting are shown in Fig. 2.

Finally, the team engaged in sharing learnings about the implementation process through various communication strategies: publishing in peer-reviewed research manuscripts, presenting at conferences and by engaging in discussions with key stakeholders. This period was sufficient to gain a deeper understanding of the philosophy, patient care process and practice management system of pharmaceutical care practice. Altogether, during this period, visions and ideas were shared between the implementation team, challenges were identified, and potential solutions scrutinized. It is strongly believed by the authors of this paper that such a thorough and lengthy preparation laid down the grounds for the forthcoming piloting stage, namely early implementation of CMM services.

Early implementation. - Once all the pre-requirements for CMM implementation were in place, the Pharmacotherapy counselling service at the HCZC initiated its work. To reach as many GPs as possible, at the outset of the project an email inviting to engage in the CMM services was sent to all GPs $(N=101)$, leaflets with all the necessary information on CMM services were printed and distributed across the HCZC facilities, a new website was created and a public health campaign with a stand dedicated to CMM services was organized. Thus, all the information on the newly commenced service was made public and widely available. Additionally, a practicing pharmacist personally visited twenty GPs located in the same building as the Pharmacotherapy counselling service to prompt them to engage in the CMM initiative. Despite all of this effort, during the first six months, the response and active engagement of the family medicine specialists was rather poor, however, it increased towards the end of the first year. Regardless of the fact that pharmacists did not share the office space with other health-care providers and were thus not highly visible on a daily basis, the recruitment of patients for the CMM services almost exclusively occurred through referral by general practitioners or self-referral. Hence, the predominance of the active search of patients by the pharmacist, as previously noted (42), was not encountered in the present study. Nevertheless, as previously described in the literature (43), it can be assumed that patient recruitment and acceptance of the service would have been more prominent, had the pharmacists shared the working space with GPs, and thus had been more visible. To allow for the standardisation of the patient care process, and consistency of CMM implementation, both pharmacists were present during all patient encounters. Thus, all uncertainties were immediately discussed and a consensus, regarding the identification of DTPs and proposed interventions, was reached.

During this stage, the team faced several challenges. One of the biggest challenges was the unawareness of medical providers of the existence of the new service at the health centre or the scope and benefits of such service regardless of the fact that they were informed, which resulted in their lack of involvement. To improve GPs' active engagement, various meetings and events were organized, ranging from presenting the CMM concept at GPs' monthly assemblies at the health centre in front of a large group of GPs to multiple one-on-one meetings to explain what CMM stands for, the potential benefit of the service to patients 
A. Brajković et al.: Implementation of medication management services at the primary healthcare level - a pilot study, Acta Pharm. 69 (2019) 585-606.

ELEMENTS ACTIVITIES
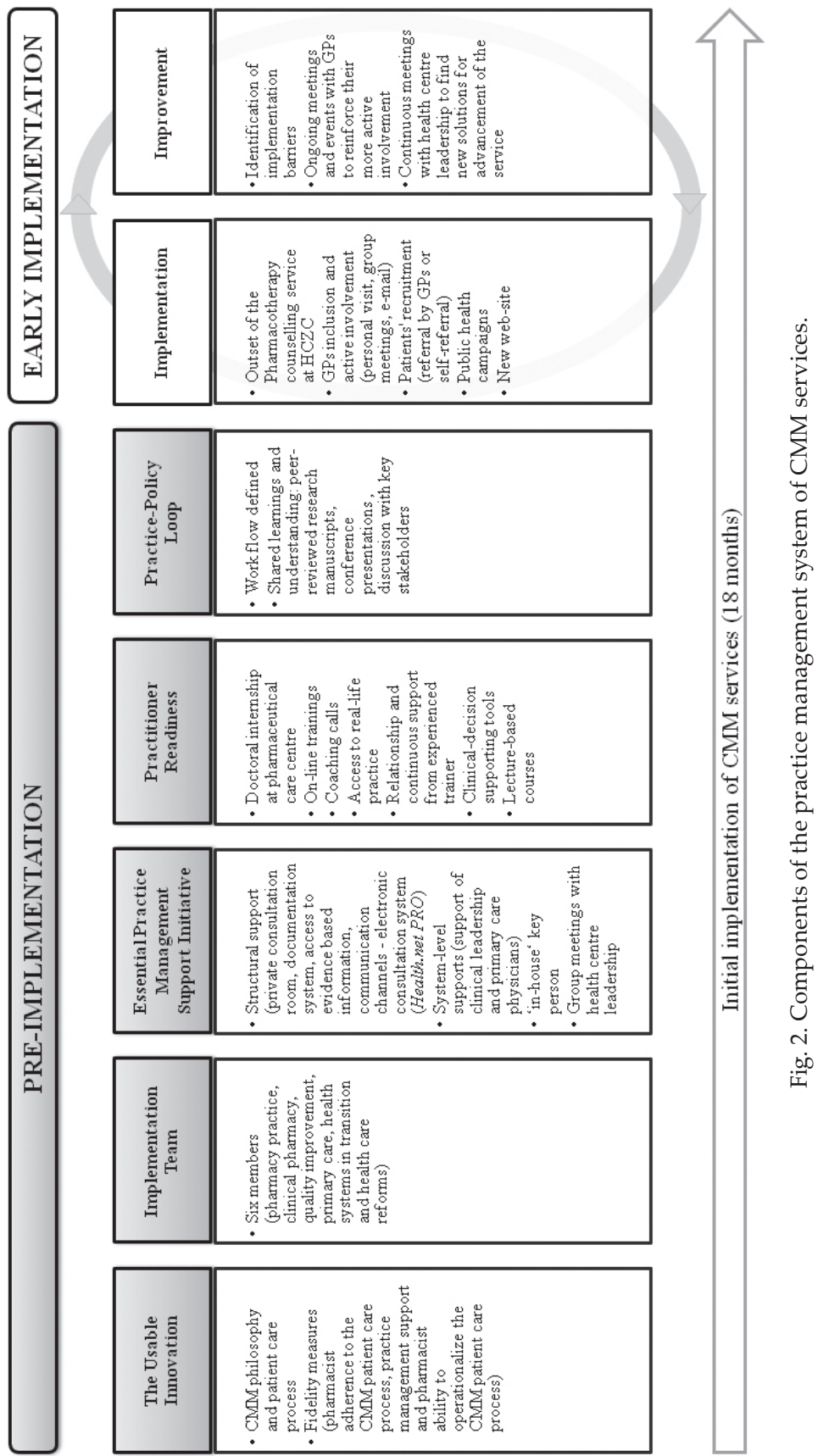
and GPs, and the steps for engaging the patient into the service. Overall, twenty one-on-one meetings with GPs were held within the first sixteen months of the piloting, and the response rate of GP's actually adopting this innovation was still rather low. Out of the total number of informed GPs $(N=101)$, only four have fully embraced the service $(3.9 \%)$ and nine have sporadically engaged with the service, that is referred $2-3$ patients altogether.

Importantly, the Head of family medicine specialists was appointed by the implementation team as the 'key person' ('champion') with the role to showcase success and share the progress of the CMM initiative with clinic leadership and practicing GPs. Even though having the champion GP was very helpful, this process of getting acceptance in the clinic was found extremely demanding, time-consuming and wearing, requiring various sets of skills, mainly to do with negotiating the introduction of a new service within an already established rigid system. Without conducting a deeper qualitative study on the underlying reasons for GPs' lack of involvement, the authors suspect that lack of time, lack of interest, forgetfulness, resistance to change as well as their frequent rotations between multiple practice sites were the main factors contributing to poor response rate. The highest success was accomplished with younger GPs, particularly those with less than 5 years of professional experience in primary health care ( $N=3$ out of four, $75 \%$ ).

In conclusion, the action research stage of this study illustrates both pre-implementation and early implementation stages of CMM in a primary care practice with all the challenges that we came across and that needed to be taken into consideration while introducing the CMM service. Moreover, it reflects other experiences and learnings from the use of the implementation system utilized for the purpose of this initiative (early implementation) $(34,43)$.

\section{Quantitative results}

Data were prospectively collected from 86 patients, of which $54(62.8 \%)$ were female. Patients' median age (overall range) was $70.5(32-87)$ years, with $73.3 \%(N=63)$ being 65 years or older. The median number (overall range) of medications per patient was 8 (2-19) and polypharmacy (more than 4 medications used) was recorded in 68 (79.1\%) patients. Cardiovascular medications were the most frequently prescribed group of medications $(42.5 \%)$. Accordingly, diseases of the circulatory system were the most prevalent conditions $(42.5 \%)$, with hypertension as the most commonly presenting condition $(82.6 \%)$. Overall, the median number (overall range) of medical conditions per patient was 5 (1-11), and $54.7 \%$ had five or more comorbidities. Detailed study sample characteristics are shown in Table I.

During the initial two visits, overall 241 DTPs were identified with an average of 2.8 DTPs $( \pm 1.6)$ per patient. At least one DTP was identified in $81(96.2 \%)$ patients, of which $30.2 \%$ had 4 or more DTPs. The most prevalent DTP was "Needs additional therapy" (26.1 $\%)$, with "Untreated condition" being the most common cause. The second most frequent DTP category was "Dosage too low" (24.5\%), followed by "Unnecessary drug therapy" (12.4\%) and "Dosage too high" (11.6\%). Only $5.0 \%$ of identified DTPs were related to non-adherence. Appendix A lists the prevalence of DTP categories, along with its causes and the most common examples. The medications most frequently associated with DTPs were pantoprazole, statins, and bisoprolol (Table II). 
A. Brajković et al.: Implementation of medication management services at the primary healthcare level - a pilot study, Acta Pharm. 69 (2019) 585-606

Table I. Study sample characteristics

\begin{tabular}{lll}
\hline Characteristic & & $\begin{array}{l}\text { Study sample } \\
(N=86)\end{array}$ \\
\hline Age, median (range) & Male & $70.5(32-87)$ \\
Sex, $N(\%)$ & Female & $32(37.2)$ \\
Smoking status, $N(\%)$ & Yes & $11(12.8)$ \\
Medications used at the initial visit, $N$ & 710 \\
Medications used per patient at the initial visit, median (range) & $8(2-19)$ \\
Use of cardiovascular system medications, $N$ (\%) (ATC class C) & $302(42.5)$ \\
Use of alimentary tract and metabolism system medications, $N$ (\%) (ATC class A) & $132(18.6)$ \\
Use of nervous system medications, $N$ (\%) (ATC class N) & $110(15.5)$ \\
Diagnoses at the initial visit, $N$ & 361 \\
Diagnoses per patient, median (range) & $4(1-9)$ \\
Most frequent diagnosis-related groups, $N$ (\%) & \\
Diseases of the circulatory system (ICD-10 I00-I99), $N(\%)$ & $147(40.7)$ \\
Endocrine, nutritional and metabolic diseases (ICD-10 E00-E99), $N(\%)$ & $81(22.4)$ \\
Diseases of the musculoskeletal system and connective tissue (ICD-10 M00-M99), N (\%) $32(12.3)$
\end{tabular}

Table II. The most common drug therapy problems associated with medications

\begin{tabular}{ccc}
\hline Medication & $\begin{array}{c}\text { Frequency of drug therapy } \\
\text { problems, } N(\%)\end{array}$ & $\begin{array}{c}\text { The most common drug therapy problem } \\
\text { category, } N(\%)\end{array}$ \\
\hline Pantoprazole & $14(5.8)$ & Unnecessary drug therapy, $5(2.1)$ \\
Statins & $13(5.4)$ & Needs additional therapy, $7(2.9)$ \\
Bisoprolol & $13(5.4)$ & Dosage too low, $6(2.5)$ \\
Amlodipine & $9(3.7)$ & Needs additional therapy, $3(1.2)$ \\
Ramipril & $9(3.7)$ & Dosage too low, $2(0.8)$ \\
Perindopril & $7(2.9)$ & Needs additional therapy, $2(0.8)$ \\
Furosemide & $7(2.9)$ & Dosage too low, 2 $(0.8)$ \\
Metformin & $7(2.9)$ & Dosage too low, $2(0.8)$ \\
Moxonidine & $7(2.9)$ & Needs additional therapy, $2(0.8)$ \\
Diazepam & $6(2.5)$ & Unnecessary drug therapy, $3(1.2)$ \\
\hline
\end{tabular}

According to the univariate analysis, several factors showed significant association with the identification of three or more DTPs: age $(p=0.010)$, employment status $(p=0.016)$, number of comorbidities $(p=0.001)$, polypharmacy $(p=0.000)$, hospitalizations in previous 
year $(p=0.107)$, hypertension $(p=0.029)$, type 2 diabetes $(p=0.010)$ and dyslipidaemia $(p=$ 0.001) (Table III). Multivariate analysis showed that patients with polypharmacy were 8.86 times more likely to have three or more DTPs than the patients using 4 or less medications $(p=0.011)$. In addition, type 2 diabetes was the second most significant factor associated with the identification of three or more DTPs $(p=0.025)$. Detailed results of multivariable logistic regression are shown in Table IV.

CMM is a patient-centred clinical service provided by specially educated pharmacists in collaboration with general practitioners and other health care providers, designed to optimize patients' drug-therapy and improve clinical outcomes (1). However, CMM services are still fairly novel at the primary care level and, for that reason, are generally not embedded in health care systems across Europe (9). Moreover, due to implementation variability

Table III. Univariate analysis of factors associated with the DTP occurrence among patients with chronic diseases receiving CMM services

\begin{tabular}{|c|c|c|c|c|c|}
\hline \multirow{2}{*}{\multicolumn{2}{|c|}{$\begin{array}{c}\text { Variable } \\
0-2\end{array}$}} & \multicolumn{2}{|c|}{ DTP (\%) } & \multirow{2}{*}{$\mathrm{OR}^{\mathrm{a}}(95 \% \mathrm{CI})^{\mathrm{b}}$} & \multirow{2}{*}{$p$-value } \\
\hline & & $\geq 3$ & & & \\
\hline \multirow{2}{*}{ Gender } & Male & 15.1 & 22.1 & 1 & - \\
\hline & Female & 23.3 & 39.5 & $1.16(0.48-2.85)$ & 0.741 \\
\hline \multirow{2}{*}{ Age } & $<65$ & 16.3 & 10.5 & 1 & - \\
\hline & $\geq 65$ & 22.1 & 51.2 & $3.60(1.33-9.75)$ & 0.010 \\
\hline \multirow{2}{*}{ Smoking status } & No & 31.4 & 55.8 & 1 & - \\
\hline & Yes & 7.0 & 5.8 & $0.47(0.13-1.68)$ & 0.332 \\
\hline \multirow{3}{*}{ Employment status } & Retired & 25.6 & 54.7 & 1 & - \\
\hline & Employed & 10.5 & 4.7 & $0.21(0.06-0.75)$ & 0.016 \\
\hline & Unemployed & 2.3 & 2.3 & $0.47(0.06-3.54)$ & 0.462 \\
\hline \multirow{2}{*}{$\begin{array}{l}\text { Number of } \\
\text { comorbidities }\end{array}$} & $1-3$ & 19.8 & 10.5 & 1 & - \\
\hline & $\geq 4$ & 18.6 & 51.2 & 5.19 (1.93-13.98) & 0.001 \\
\hline \multirow{2}{*}{$\begin{array}{l}\text { Polypharmacy (more } \\
\text { than } 4 \text { medications) }\end{array}$} & No & 17.4 & 3.5 & 1 & - \\
\hline & Yes & 20.9 & 58.1 & 13.89 (3.59-53.66) & 0.000 \\
\hline \multirow{2}{*}{$\begin{array}{l}\text { Hospitalization in } \\
\text { previous year }\end{array}$} & No & 34.9 & 3.5 & 1 & - \\
\hline & Yes & 47.7 & 14.0 & $2.93(0.76-11.29)$ & 0.107 \\
\hline \multirow{2}{*}{$\begin{array}{l}\text { Emergency department } \\
\text { visit in previous year }\end{array}$} & No & 29.1 & 53.5 & 1 & - \\
\hline & Yes & 9.3 & 8.1 & $0.48(0.15-1.46)$ & 0.190 \\
\hline \multirow{2}{*}{ Hypertension } & No & 8.1 & 30.0 & 1 & - \\
\hline & Yes & 30.2 & 65.8 & 4.49 (1.07-18.81) & 0.029 \\
\hline \multirow{2}{*}{ Type 2 diabetes } & No & 31.4 & 33.7 & 1 & - \\
\hline & Yes & 7.0 & 27.9 & $3.70(1.32-10.50)$ & 0.010 \\
\hline \multirow{2}{*}{ Dyslipidaemia } & No & 26.7 & 20.9 & 1 & - \\
\hline & Yes & 11.6 & 40.7 & 4.47 (1.76-11.39) & 0.001 \\
\hline
\end{tabular}

${ }^{\mathrm{a}} \mathrm{OR}$ - odds ratio; ${ }^{\mathrm{b}} \mathrm{CI}$ - confidence interval 
across various clinical settings, patient types and practitioners, delivery of CMM services still appears to be inconsistent and its implementation process relatively poorly documented (34). Therefore, this manuscript innovates as it provides an in-depth description of the process of the initial implementation of CMM services at a primary care practice site, thus adding important knowledge about both the process of implementation of pharmacist-led care delivery models and the most prevalent drug-therapy problems experienced by Croatian patients in the real world.

To the best of authors' knowledge, this is the first study providing an exhaustive research-based depiction of the process of the initial implementation of CMM in Croatia and Europe. The narrative provided here presents the footsteps and strategies to assist willing practitioners to successfully introduce this new service in health care systems. Even more, this study describes some of the topics that need to be reflected upon to prepare a 'new pharmacist', a professional with a completely different set of competencies required for the assimilation of a new professional practice, pharmaceutical care practice, and the provision of patient-centred services $(1,9,44)$. Namely, the traditional education provided at most universities worldwide does not prepare pharmacists to work as patient-centred health-care providers, neither professionals with competencies to work as a part of a multidisciplinary team. Although graduate curricula highlight the importance of inter-disciplinarity, the science-practice gap still remains unabridged $(44,45)$.

As the project unfolded, it became clear that the responsibilities and functions of pharmaceutical care practitioners are very different from those of community pharmacists. Action

Table IV. Multivariate analysis of factors associated with the DTP occurrence among patients with chronic diseases receiving CMM services

\begin{tabular}{lccc}
\hline Variable & & $\mathrm{OR}^{\mathrm{a}}\left(95 \% \mathrm{CI}^{\mathrm{b}}\right)$ & $p$-value \\
\hline Age & $<65$ & 1 & - \\
& $\geq 65$ & $2.75(0.32-23.75)$ & 0.359 \\
Employment status & Retired & 1 & - \\
& Employed & $0.65(0.05-8.46)$ & 0.738 \\
Number of comorbidities & Unemployed & $0.68(0.03-17.70)$ & 0.819 \\
Polypharmacy & $1-3$ & 1 & - \\
(more than 4 medications) & $\geq 4$ & $1.14(0.26-4.95)$ & 0.865 \\
Hospitalization in previous & No & 1 & - \\
year & Yes & $8.86(1.66-47.37)$ & 0.011 \\
Hypertension & No & 1 & - \\
& Yes & $2.41(0.46-12.79)$ & 0.301 \\
Type 2 diabetes & No & 1 & - \\
& Yes & $0.71(0.10-5.03)$ & 0.735 \\
Dyslipidaemia & No & 1 & - \\
& Yes & $4.76(1.21-18.66)$ & 0.025 \\
\hline
\end{tabular}

${ }^{a} \mathrm{OR}$ - odds ratio

${ }^{\mathrm{b}} \mathrm{CI}$ - confidence interval 
research became a valuable mechanism that instigated the team or pharmacists/researchers to think about its responsibilities within the context of primary care outside the community pharmacy setting. To provide CMM services, pharmacists had to accept co-responsibility for patients' clinical outcomes, thus becoming like the other members of the health care team, and finally to recreate their identity as patient-centred healthcare professionals. As already confirmed in previous research (16), pharmacists can feel fearful and insecure to assume new roles that imply being held accountable for patients' clinical outcomes. As stressed by Rosenthal et al. (46), staying in one's own familiar environment and avoiding leaving one's comfort zone is ingrained in pharmacist's culture. In addition, as revealed in other studies $(16,47-49)$, action research encouraged individual and group reflections on new circumstances and allowed for the conception of the most fitting organizational model for an efficient implementation of CMM services.

This study showed how challenging it is to introduce a new service into a rigid and already established health care system. As the project progressed, several challenges were encountered: a) resistance of GPs to embrace the new service available at their premises; $b$ ) lack of experience of both practising pharmacists in establishing collaboration with GPs and working in a multidisciplinary team; and c) defining the new work process necessary to provide a standardized and reproducible service. The latter two were mastered throughout the course of the project, while the first one still remains a challenge for researchers/practitioners. Finally, the initial implementation of the pharmacy service demanded major work as new collaborative channels with GPs were initiated and, consequently profound transformation in pharmacists' role. Again, the utilized research methodology became an excellent approach that allowed change to occur.

Moreover, this is the first Croatian study that evaluated the incidence and type of DTPs in ambulatory patients, thus providing insights regarding the types of medication problems patients experience at the primary care level in Croatia. The high number of patients with one or more identified DTPs was similar to the rates noted in previous research $(9,17,18,24)$, demonstrating how CMM services add value to the current standard of care patients are receiving in Croatian health care system. Moreover, consistent with previous evaluations of CMM practices, the two most common DTPs were "Needs additional therapy" and "Dosage too low" $(17,18,23)$, suggesting that the major DTP in present population is the underutilization of effective medications. This finding is quite contrary to the assumption that pharmacists' major role is to reduce the number of medications and medication costs for patients. As showed by Isetts et al. (23), the economic impact of CMM services is mainly due to a significant decrease in the total costs of health care, instead of a decrease in medication costs. By helping patients to reach their therapeutic goals, CMM pharmacists can enhance health outcomes, and thus impacting the overwhelming costs associated with bad outcomes. In addition, "Adherence" was one of the least commonly presented DTPs. Although pharmacy practice tends to focus on patients' adherence, low prevalence of non-adherence problems in the current and previous studies $(9,18)$ point to the importance of following the rational decision-making process proposed by pharmaceutical care practice, which means firstly ensuring that every medication is appropriate, effective and safe for a specific patient, and only in the end guaranteeing that the patient is willing and able to take their medications (50).

This study is one of the first research to have determined the factors associated with the occurrence of DTPs at the primary care level (24), by employing the theoretical framework proposed by Cipolle et al. Moreover, it appears to be the first study to have established 
DTP-associated factors among general ambulatory patients, by using the aforementioned methodology. In line with published evidence $(24,28,29)$, polymedicated patients were more likely to have a higher number of DTPs. The second characteristic most strongly associated with the occurrence of three or more DTPs was type 2 diabetes. Both of the above-mentioned factors associated with the DTP occurrence could be used as screening criteria for patients' referral to CMM services, since those types of patients potentially have higher drug-related needs and therefore, could benefit more from the service. Consistently, results of this study provide information to better tailor the training of practitioners, so that encountered DTPs could be more efficiently identified, resolved and prevented.

\section{CONCLUSIONS}

The action research methodology enabled an effective approach to introducing a new pharmacist-led service in the Croatian primary health care, as well as detecting the challenges encountered throughout the process of the initial implementation of CMM services. The challenges encountered should be tackled for full implementation of CMM services and need to be taken into consideration in the future implementation of this service in other health care settings. Additionally, a deeper understanding of work processes and resources needed for the initial implementation of CMM were of paramount importance for a successful introduction of CMM within a primary care setting.

The high incidence of DTPs identified among patients with chronic conditions at the primary care level indicates the need for pharmaceutical care services in this population. Type 2 diabetic patients and patients using five or more medications should be prioritized for CMM services as potentially they could have a higher number of drug therapy problems and could, therefore, have a greater benefit from the service. The analysis provided in this study refers to the need for tailoring a targeted education for practitioners, so that encountered DTPs could be more efficiently identified, resolved and prevented. Further research is needed to establish the impact of provided care on clinical outcomes in the Croatian health care setting.

\section{REFERENCES}

1. T. McInnis, L. Strand and C. E. Webb, Integrating Comprehensive Medication Management to Optimize Patient Outcomes, Resour. Guid. (2012) A-26.

2. Institute of Medicine, Informing the Future: Critical Issues in Health: Fourth Edition, The National Academies Press, Washington DC 2007; https://doi.org/10.17226/12014

3. OECD/EU, Health at a Glance: Europe 2018: State of Health in the EU Cycle, OECD Publishing, Paris/EU, Brussels 2018; https://doi.org/10.1787/health_glance_eur-2018-en

4. World Health Organization, Noncommunicable diseases key facts, June 2018; https://www.who.int/ news-room/fact-sheets/detail/noncommunicable-diseases; access date April 29, 2019.

5. J. H. Watanabe, T. McInnis and J. D. Hirsch, Cost of Prescription Drug-Related Morbidity and Mortality, Ann. Pharmacother. 52 (2018) 829-837; https://doi.org/10.1177/1060028018765159

6. F. R. Ernst and A. J. Grizzle, Drug-related morbidity and mortality: Updating the cost-of-illness model, J. Am. Pharm. Assoc. 41 (2001) 192-199; https://doi.org/10.1016/S1086-5802(16)31229-3

7. J. A. Johnson and J. L. Bootman, Drug-related morbidity and mortality and the economic impact of pharmaceutical care, Am. J. Health-Syst. Pharm. 54 (1997) 554-558; https://doi.org/10.1093/ajhp/54.5.554 
8. K. Wiedenmayer, R. S. Summers; C. A. Mackie, A. G. S. Gous, M. Everard and D. Tromp, Developing pharmacy practice - A focus on patient care, World Health Organization and International Pharmaceutical Federation, Geneva and The Hague 2006; https://apps.who.int/iris/handle/10665/69399; access date April 29, 2019.

9. R. J. Cipolle, L. M. Strand and P. C. Morley, Pharmaceutical Care Practice: The Patient-Centered Approach to Medication Management, $3^{\text {rd }}$ ed., The McGraw-Hill Companies, New York 2012.

10. Public Law, 117 STAT. 2066, PUBLIC LAW 108-173-DEC. 8, 2003, The Medicare Prescription Drug, Improvement, and Modernization Act of 2003, December 2003; https://www.govinfo.gov/app/details/ PLAW-108publ173; access date April 29, 2019.

11. I. Torjesen, More than 400 pharmacists will be recruited to GP surgeries by next year, BMJ 351 (2015) Article ID h6167 (2 pages); https://doi.org/10.1136/bmj.h6167

12. Australian Medical Association, Analysis of non-dispensing pharmacists in general practice clinics, Deloitte Access Economics, Sydney 2015; https://www2.deloitte.com/au/en/pages/economics/articles/analysis-non-dispensing-pharmacists-general-practice-clinics.html; access date April 29, 2019.

13. L. Dolovich, K. Pottie, J. Kaczorowski, B. Farrell, Z. Austin, C. Rodriguez, K. Gaebel and C. Sellors, Integrating family medicine and pharmacy to advance primary care therapeutics, Clin. Pharmacol. Ther. 83 (2008) 913-917; https://doi.org/10.1038/clpt.2008.29

14. S. de A. M. Mendonça, A. C. Melo, G. C. C. Pereira, D. M. de S. S. dos Santos, E. B. Grossi, M. do C. V. B. Sousa, D. R. de Oliveira and A. C. Soares, Clinical outcomes of medication therapy management services in primary health care, Braz. J. Pharm. Sci. 52 (2016) 365-373; http://dx.doi.org/10.1590/s198482502016000300002

15. A. O. M. Mourão, W. R. Ferreira, M. A. P. Martins, A. M. M. Reis, M. R. G. Carrillo, A. G. Guimarães and L. S. Ev, Pharmaceutical care program for type 2 diabetes patients in Brazil: A randomised controlled trial, Int. J. Clin. Pharm. 35 (2013) 79-86; https://doi.org/10.1007/s11096-012-9710-7

16. G. C. B. de Oliveira, M. R. Alves and D. R. de Oliveira, Action Research as a Tool for Transformation of the Pharmacist's Praxis in Primary Care, Int. J. Pharm. Pharm. Sci. 9 (2017) 180-185; https://doi. org/10.22159/ijpps.2017v9i3.16486

17. L. M. Strand, R. J. Cipolle, P. C. Morley and M. J. Frakes, The impact of pharmaceutical care practice on the practitioner and the patient in the ambulatory practice setting: twenty-five years of experience, Curr. Pharm. Des. 10 (2004) 3987-4001; https://doi.org/10.2174/1381612043382576

18. D. R. de Oliveira, A. R. Brummel and D. B. Miller, Medication therapy management: 10 years of experience in a large integrated health care system, J. Manag. Care Spec Pharm. 16 (2010) 185-195; https:// doi.org/10.18553/jmcp.2010.16.3.185

19. D. Rao, A. Gilbert, L. M. Strand and R. J. Cipolle, Drug therapy problems found in ambulatory patient populations in Minnesota and South Australia, Pharm. World Sci. 29 (2007) 647-654; https://doi. org/10.1007/s11096-007-9123-1

20. L. G. Planas, K. M. Crosby, K. D. Mitchell and K. C. Farmer, Evaluation of a hypertension medication therapy management program in patients with diabetes, J. Am. Pharm. Assoc. 49 (2009) 164-170; https://doi.org/10.1331/JAPhA.2009.08164

21. A. Brummel and A. M. Carlson, Comprehensive Medication Management and Medication Adherence for Chronic Conditions, J. Manag. Care Spec. Pharm. 22 (2016) 56-62; https://doi.org/10.18553/ jmcp.2016.22.1.56

22. C. W. Cranor, B. A. Bunting and D. B. Christensen, The Asheville Project: Long-term clinical and economic outcomes of a community pharmacy diabetes care program, J. Am. Pharm. Assoc. 43 (2003) 173-184; https://doi.org/10.1331/108658003321480713

23. B. J. Isetts, S. W. Schondelmeyer, M. B. Artz, L. a Lenarz, A. H. Heaton, W. B. Wadd, L. M. Brown and R. J. Cipolle, Clinical and economic outcomes of medication therapy management services: the Minnesota experience, J. Am. Pharm. Assoc. 48 (2008) 203-214; https://doi.org/10.1331/JAPhA.2008.07108

24. K. B. Detoni, I. V Oliveira, M. M. G. Nascimento, T. R. Caux, M. R. Alvares and D. R. de Oliveira, Impact of a medication therapy management service on the clinical status of patients with chronic 
obstructive pulmonary disease, Int. J. Clin. Pharm. 39 (2016) 95-103; https://doi.org/10.1007/s11096016-0402-6

25. P. R. Obreli-Neto, S. Marusic, C. M. Guidoni, A. de O. Baldoni, R. D. Renovato, D. Pilger, R. K. N. Cuman and L. R. L. Pereira, Economic evaluation of a pharmaceutical care program for elderly diabetic and hypertensive patients in primary health care: a 36-month randomized controlled clinical trial, J. Manag. Care Spec. Pharm. 21 (2015) 66-75; https://doi.org/10.18553/jmcp.2015.21.1.66

26. H. Schultz, S. M. Westberg, D. R. de Oliveira and A. Brummel, Patient-perceived value of Medication Therapy Management (MTM) services: a series of focus groups, Innov. Pharm. 3 (2012) Article ID 96 (8 pages); https://doi.org/10.24926/iip.v3i4.278

27. D. G. Garrett and L. A. Martin, The Asheville Project: Participants' perceptions of factors contributing to the success of a patient self-management diabetes program, J. Am. Pharm. Assoc. 43 (2003) 185-190; https://doi.org/10.1331/108658003321480722

28. O. A. Abdela, A. S. Bhagavathula, H. Getachew and Y. Kelifa, Risk factors for developing drug-related problems in patients with cardiovascular diseases attending Gondar University Hospital, Ethiopia, J. Pharm. BioAllied Sci. 8 (2016) 289-295; https://doi.org/10.4103/0975-7406.199335

29. Y. L. Niriayo, K. Kumela, T. D. Kassa and M. T. Angamo, Drug therapy problems and contributing factors in the management of heart failure patients in Jimma University Specialized Hospital, Southwest Ethiopia, PLoS One 13 (2018) Article ID e0206120 (14 pages); https://doi.org/10.1371/journal. pone.0206120

30. S. I. Al-Azzam, K. H. Alzoubi, S. Aburuz and Q. Alefan, Drug-related problems in a sample of outpatients with chronic diseases: A cross-sectional study from Jordan, Ther. Clin. Risk Manag. 12 (2016) 233-239; https://doi.org/10.2147/TCRM.S98165

31. O. Urbina, O. Ferrández, S. Luque, S. Grau, S. Mojal, R. Pellicer, M. Riu, E. Salas and J. Comin-Colet, Patient risk factors for developing a drug-related problem in a cardiology ward, Ther. Clin. Risk Manag. 11 (2014) 9-15; https://doi.org/10.2147/TCRM.S71749

32. K. Lewin, Field Theory In Social Science; Selected Theoretical Papers (D. Cartwright, Ed.). Harper \& Brothers Publisher New York, New York 1976.

33. C. Blanchard, M. Livet, C. Ward, L. Sorge, T. D. Sorensen and M. R. McClurg, The active implementation frameworks: A roadmap for advancing implementation of comprehensive medication management in primary care, Res. Social Adm. Pharm. 13 (2017) 922-929; https://doi.org/10.1016/j. sapharm.2017.05.006

34. M. Livet, C. Blanchard, T. D. Sorensen and M. R. McClurg, An implementation system for medication optimization: Operationalizing comprehensive medication management delivery in primary care, J. Am. Coll. Clin. Pharm. 1 (2018) 14-20; https://doi.org/10.1002/jac5.1037

35. Health Centre Zagreb - Centre and MCS Grupa d.o.o., Health.net PRO (Zdravlje.net PRO), https://dzzcentar.hr/projekti/zdravlje-net-pro/; access date April 29, 2019.

36. A. Bowling, Research Methods in Health: investigating health and health services, $3^{\text {rd }}$ ed., The McGraw-Hill Companies, New York 2009, pp. 222-223.

37. D. L. Pestka, L. A. Sorge, M. R. McClurg and T. D. Sorensen, The Philosophy of Practice for Comprehensive Medication Management: Evaluating Its Meaning and Application by Practitioners, Pharmacotherapy 38 (2018) 69-79; https://doi.org/10.1002/phar.2062

38. The Agency for Medicinal Products and Medical Devices, Croatia, Medicinal Products Database, 2019; http://www.halmed.hr/en/Lijekovi/Baza-lijekova/; access date April 20, 2019.

39. J. T. DiPiro, R. L. Talbert, G. C. Yee, G. R. Matzke, B. G. Wells, L. M. Posey, Pharmacotherapy A Pathophysiologic Approach, 10 ${ }^{\text {th }}$ ed., McGraw-Hill Education, New York 2017.

40. D. L. Krinsky, S. P. Ferreri, B. Hemstreet, A. L. Hume, G. D. Newton, C. J. Rollins, K. J. Tietze, Handbook of Nonprescription Drugs: An Interactive Approach to Self-Care, $19^{\text {th }}$ ed., American Pharmacists Association, Washington, DC 2018; https://doi.org/10.21019/9781582122656 
41. UpToDate, Post, TW (Ed), UpToDate, Waltham, MA 2019; https://www.uptodate.com/contents/search; access date April 20, 2019.

42. P. A. do Amaral, S. de A. M. Mendonça, D. R. de Oliveira, L. J. Peloso, R. D. S. Pedroso and M. Â. Ribeiro, Impact of a medication therapy management service offered to patients in treatment of breast cancer, Braz. J. Pharm. Sci. 54 (2018) Article ID e00221 (12 pages); http://dx.doi.org/10.1590/ s2175-97902018000200221

43. D. R. de Oliveira, Pharmaceutical care uncovered: an ethnographic study of pharmaceutical care practice, University of Minnesota, Minneapolis 2003.

44. S. de A. M. Mendonça, E. L. de Freitas and D. R. de Oliveira, Competencies for the provision of comprehensive medication management services in an experiential learning project, PLoS One 12 (2017) e0185415 (14 pages); https://doi.org/10.1371/journal.pone.0185415

45. E. L. de Freitas and D. R. de Oliveira, Critical thinking in the context of clinical practice: The need to reinvent pharmacy education, Rev. Port. Educ. 28 (2015) 231-250; https://doi.org/10.21814/rpe.7753

46. M. Rosenthal, Z. Austin and R. T. Tsuyuki, Are pharmacists the ultimate barrier to pharmacy practice change?, Can. Pharm. J. 143 (2010) 37-42; https://doi.org/10.3821/1913-701X-143.1.37

47. M. Â. Ribeiro, S. A. M. Araújo, M. Mendonça, A. F. R. Filardi, A. C. Y. dos Anjos and D. R. de Oliveira, Implementation and systematization of a comprehensive medication management (CMM) service delivered to women with breast cancer, Asian J. Pharm. Clin. Res. 11 (2018) 228-235; https://doi. org/10.22159/ajpcr.2018.v11i1.21537

48. A. B. Blondal, S. K. Sporrong and A. B. Almarsdottir, Introducing Pharmaceutical Care to Primary Care in Iceland - An Action Research Study, Pharmacy (Basel) 5 (2017) 23 (11 pages); https://doi. org/10.3390/pharmacy5020023

49. L. S. Nørgaard and E. W. Sørensen, Action research methodology in clinical pharmacy: how to involve and change, Int. J. Clin. Pharm. 38 (2016) 739-745; https://doi.org/10.1007/s11096-016-0310-9

50. T. D. Sorensen, D. L. Pestka, A. R. Brummel, D. J. Rehrauer and M. J. Ekstrand, Seeing the forest through the trees: improving adherence alone will not optimize medication use, J. Manag. Care Spec. Pharm. 22 (2016) 598-604; https://doi.org/10.18553/jmcp.2016.22.5.598 


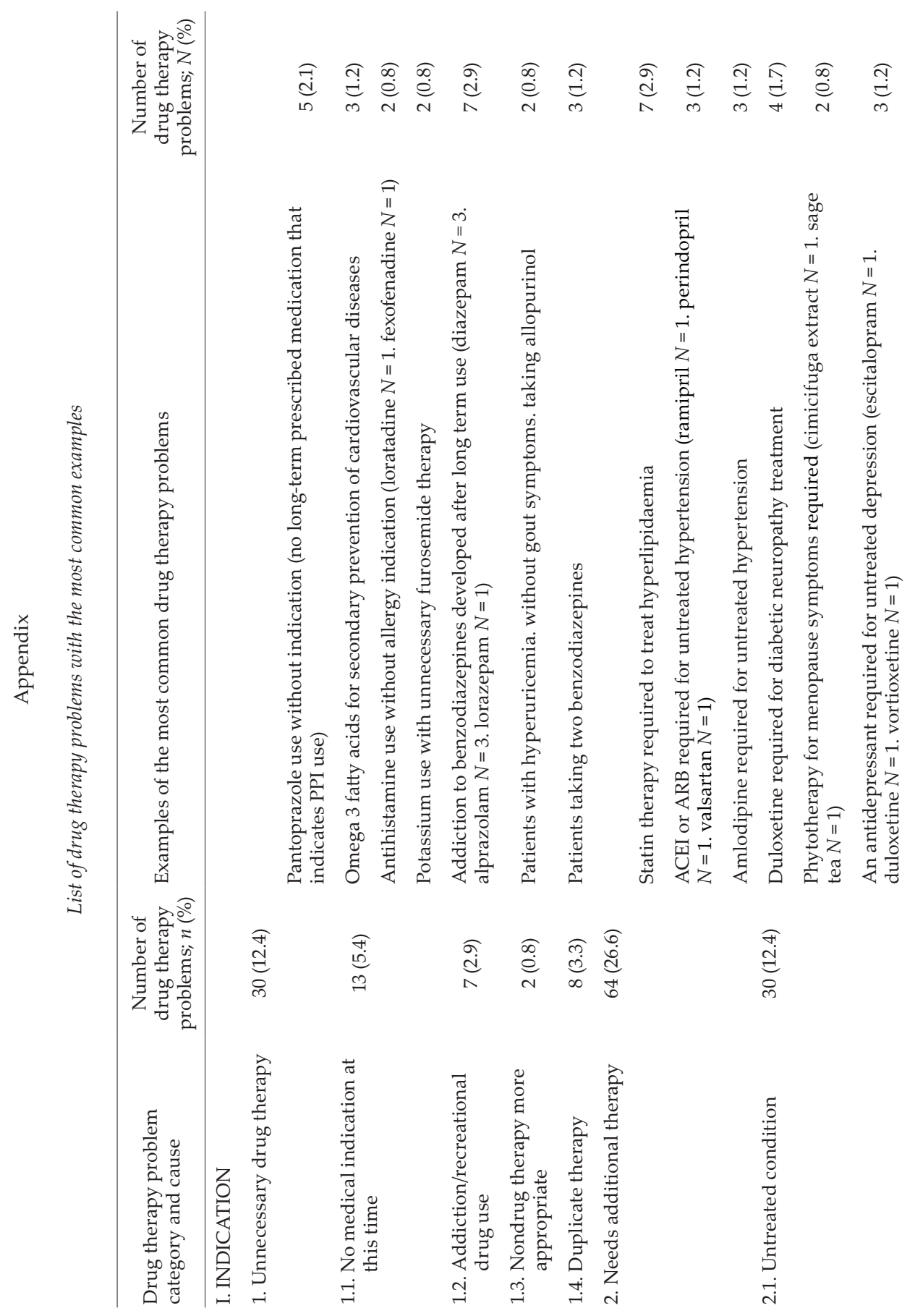




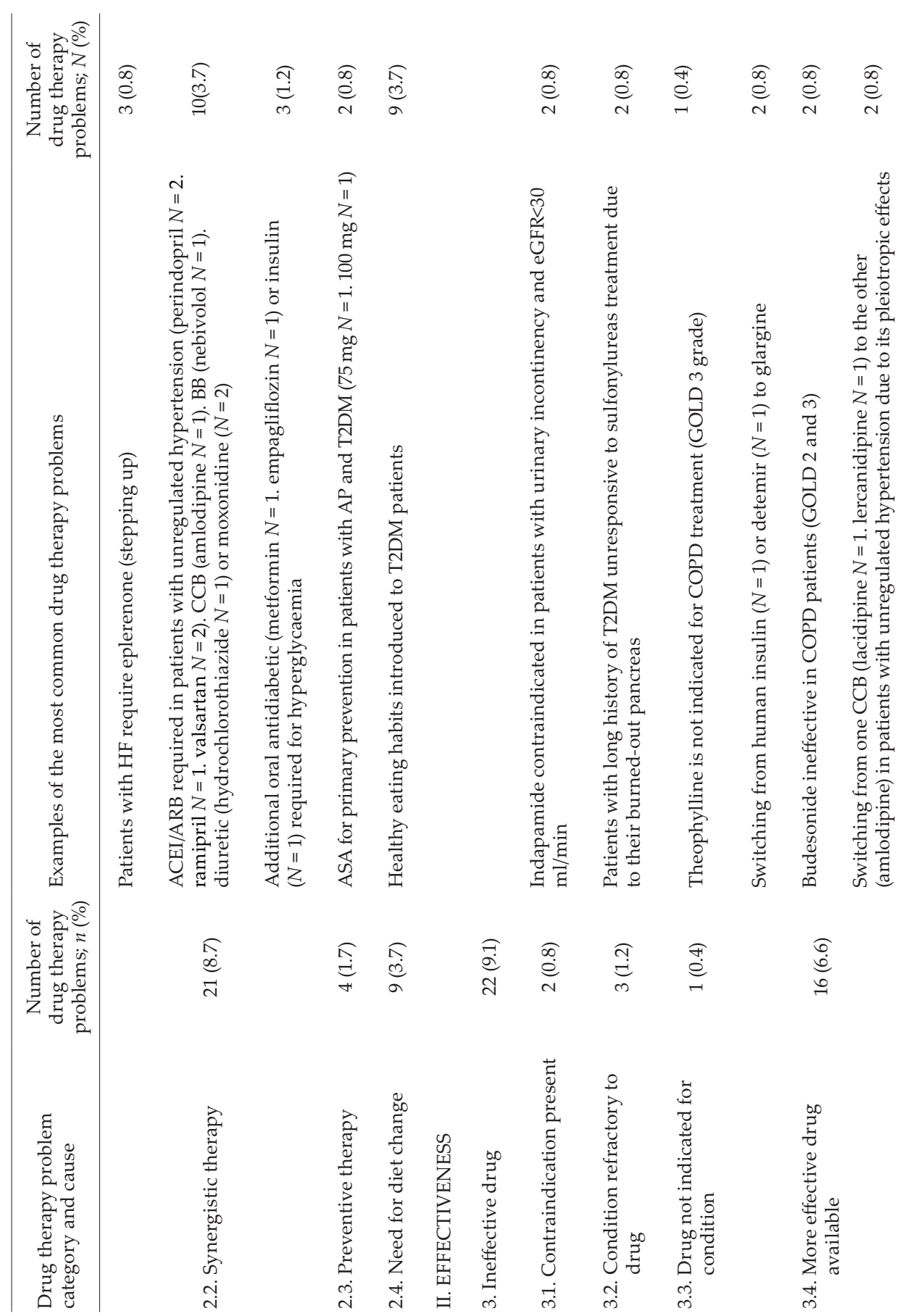




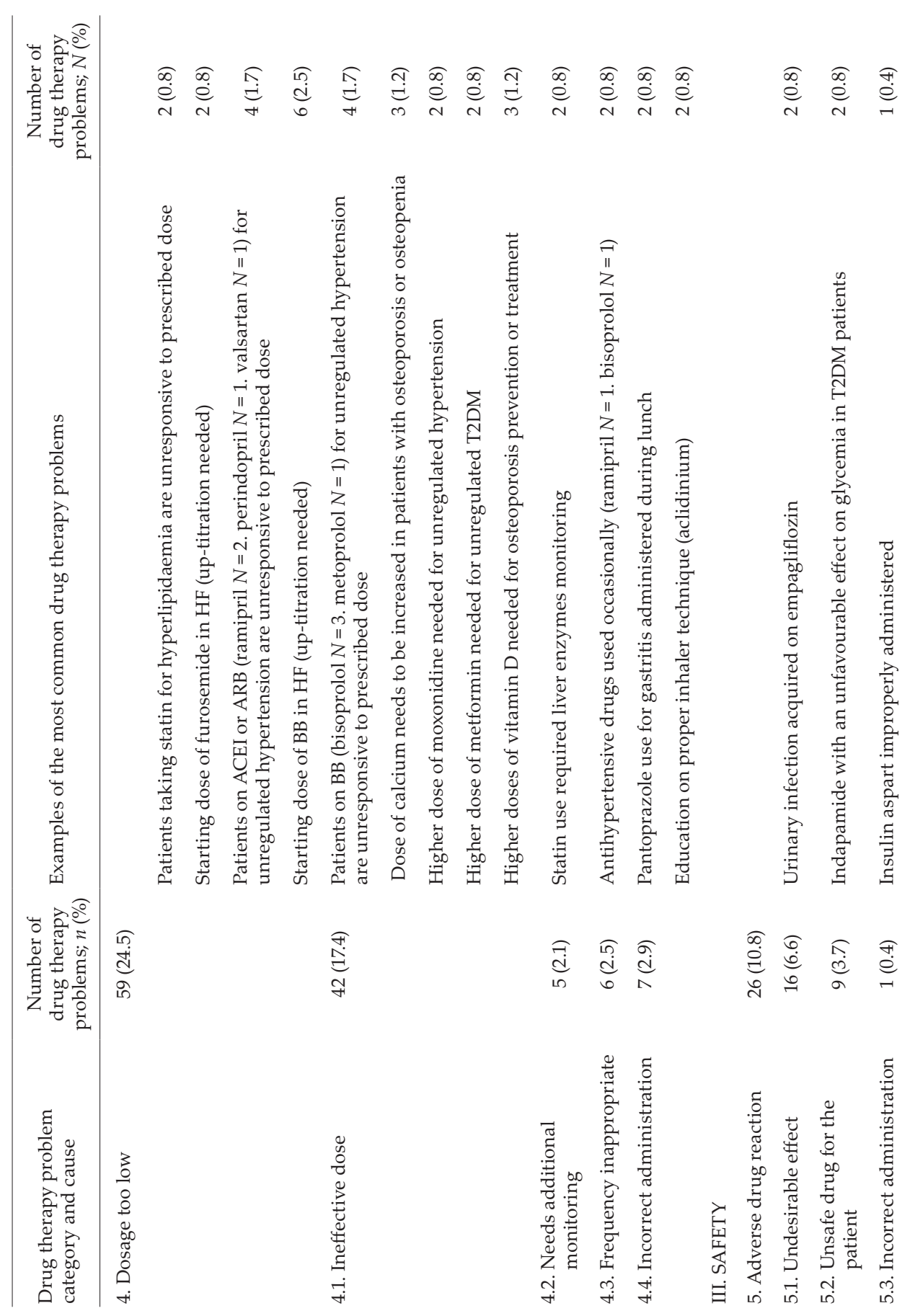




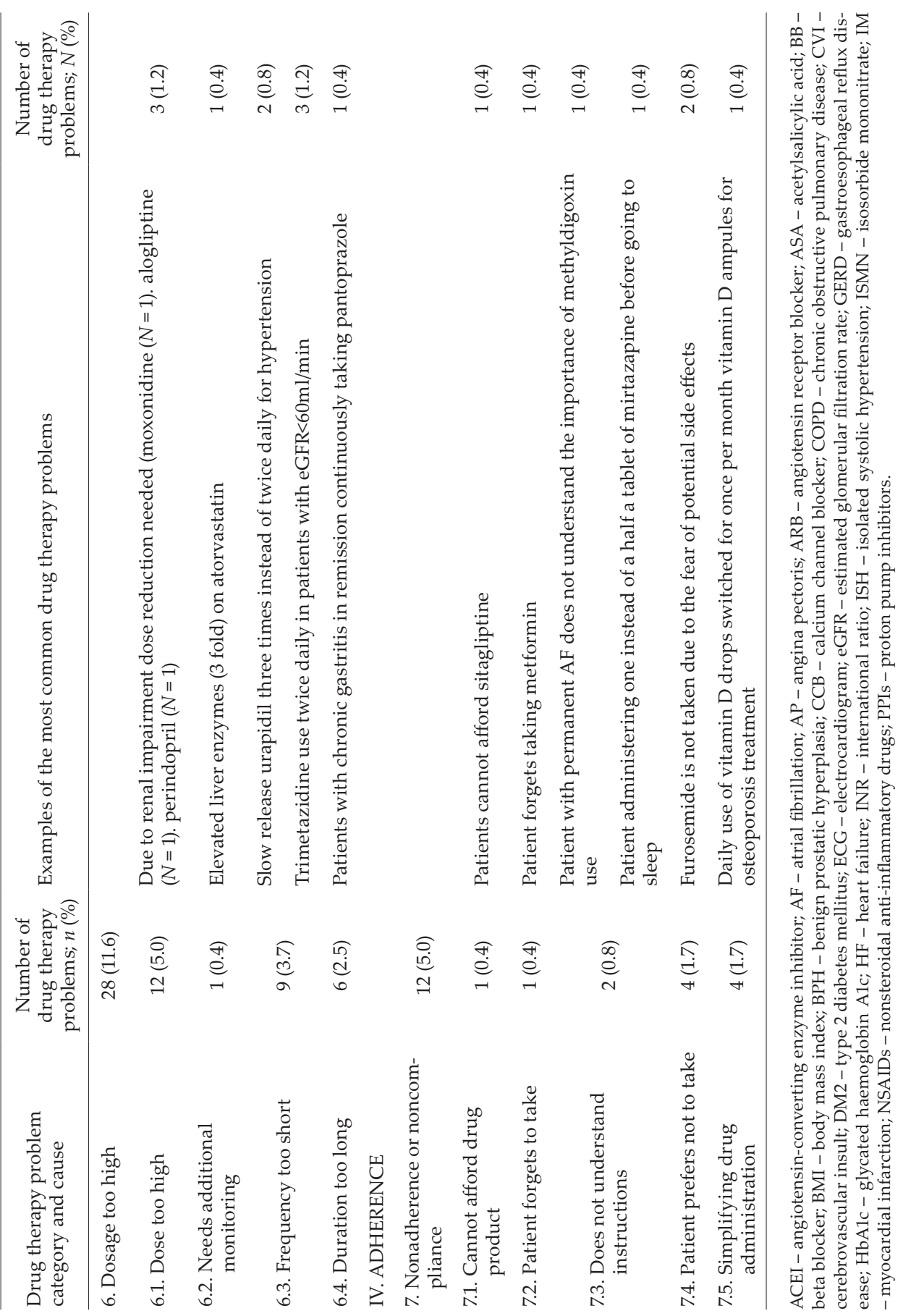

